\title{
Plasma Lipids and Lipoproteins in Young Insulin-Dependent Diabetic Patients: Relationship with Control
}

\author{
M. F. Lopes-Virella ${ }^{1}$, H. J. Wohltmann ${ }^{2}$, C. B. Loadholt ${ }^{3}$ and M. G. Buse ${ }^{1}$ \\ ${ }^{1}$ Department of Medicine, Endocrinology-Metabolism-Nutrition Division, ${ }^{2}$ Department of Pediatrics, Endocrine Section, \\ and ${ }^{3}$ Department of Biometry, Medical University of South Carolina and V. A. Medical Center, Charleston, South Carolina, USA
}

Summary. Plasma and lipoprotein cholesterol and triglycerides, glucose and haemoglobin $\mathrm{A}_{1 \mathrm{c}}$ concentrations were measured in 106 patients (56 males) with insulin-dependent diabetes mellitus (age range 2-22 years) and 36 normal volunteers (19 males) with similar age and sex distribution. The diabetic patients were further divided into three subgroups: "good", fair and poor control, based on $24 \mathrm{~h}$ glycosuria and haemoglobin $A_{1 c}$ concentrations. Total, low density lipoprotein and very low density lipoprotein cholesterol levels were significantly increased in male patients in poor control when compared with the group in "good" control and with normal subjects. Triglyceride and very low density lipoprotein triglyceride levels were also significantly increased in poorly controlled males. The most significant difference however was a decrease of high density lipoprotein cholesterol in male patients in poor control. There was a significant inverse correlation between haemoglobin $A_{1 c}$ and high density lipoprotein cholesterol $(r=-0.63)$ and a direct correlation between haemoglobin $\mathrm{A}_{1 \mathrm{c}}$ and low density lipoprotein cholesterol $(\mathrm{r}=0.35)$ and triglycerides $(\mathrm{r}=0.62)$ in the male diabetics. The findings were similar in females. The most striking change was observed in low density lipoprotein cholesterol levels, which were more markedly increased in poorly controlled females than in poorly controlled males. No statistical singificant differences were found between the groups in good and fair control for any of the plasma and lipoprotein lipids studied. A significant difference however was found between the groups in poor and fair control. There was a significant correlation in females between haemoglobin $\mathrm{A}_{1 \mathrm{c}}$ and low density lipoprotein cholesterol levels $(\mathrm{r}=0.43)$, haemoglobin $\mathrm{A}_{1 \mathrm{c}}$ and triglycerides levels $(r=0.54)$ and an inverse correlation between haemoglobin $A_{1 c}$ and high density lipoprotein cholesterol $(\mathrm{r}=-0.59)$.
Key words: Lipoproteins, HDL, LDL, VLDL, cholesterol, triglycerides, insulin-dependent diabetes, control, haemoglobin $\mathrm{A}_{1 \mathrm{c}}$.

The high incidence of coronary heart disease in insulin dependent patients with diabetes mellitus has been recognized for a long time $[1,2]$, but the predisposing factors are not fully understood. Elevated serum lipid and lipoprotein levels have been implicated as aetiological agents involved in the premature incidence of coronary heart disease in this group of patients [3-7].

We reported low levels of high density lipoprotein (HDL) cholesterol in non-insulin dependent diabetic patients with atherosclerotic macrovascular complications [8]. These findings were similar to those observed in non-diabetic patients with atherosclerosis where an inverse correlation between HDL and the incidence of coronary heart disease has been reported by several authors [9-12]. In a group of adult insulin independent male diabetics without macrovascular disease, we found low levels of HDL cholesterol when the patients were poorly controlled. In contrast, adult, well controlled diabetic subjects showed no difference from normal controls [13].

Recently Nikkila and Hormila [14] reported an increase of HDL cholesterol levels in an insulin dependent population (mean age 47 years) when compared with normal subjects. No difference was found in their studies between well and poorly controlled diabetics. In contrast Chase and Glasgow [15] found decreased levels of HDL in a group of insulin dependent children in good metabolic control.

In view of the controversy that seems to exist mainly in the insulin dependent diabetic group, we have performed quantitative analyses of plasma 
lipids and lipoproteins in 106 patients with insulindependent diabetes. The main objective of this investigation was to determine whether or not the control of diabetes influences the levels of plasma lipoproteins in this group of patients.

\section{Subjects and Methods}

\section{Patients}

One hundred and six young subjects (56 males and 50 females), with insulin-dependent diabetes were studied. Twenty-three percent of the males and $52 \%$ of the females were black, the rest were Caucasoid. All of them were recruited from an out-patient clinic where they had been followed regularly by one of us. There was no previous selection of the patients based on the control of their diabetes or previous lipid determinations. The mean age of the males was $12 \pm 0.5$ (SEM) years (range 2-22 years). The duration of their disease varied from 6 months to 19 years, with a mean duration of $5 \pm 0.5$ years. The females were slightly older with a mean age of $14 \pm 0.4$ years (range $4.5-20$ years). The mean duration of their disease was $6 \pm 0.5$ years, ranging from 6 months to 14 years.

The height and weight of the patients were normally distributed for their age; 81 and $82 \%$ were within the $25-75$ percentile for height and weight respectively; 7.5 and $9 \%$ were in the $75-97$ percentile for height and weight and 6.5 and $4 \%$ between the $3-25$ percentile. Five percent of the patients were above the 97 percentile for height and weight, but they were within $10 \%$ of ideal body weight for their height (Growth charts, National Center for Health Statistics and Center for Disease Control, US Public Health Service). None of the patients had a history of habitual alcohol intake or of taking medications other than insulin except for three siblings who were receiving chlorpropamide for diabetes insipidus. All of them received two doses per day of a mixture of intermediate and short acting insulins (Lilly mixed beef and pork insulin). The mean daily dose of insulin ( $\mathbf{U} / \mathrm{kg}$ body weight) was 0.82 for males (0.39-1.31) and 0.9 for females (0.33-1.43).

Only two patients showed mild background retinopathy which was documented by a fluorescein angiogram. Another patient had had metabolic cataracts in the past which had been operated but no signs of retinopathy were present. None of the patients had symptoms or physical signs suggestive of neuropathy. Nerve conduction studies were not performed.

Renal function was evaluated in all patients by measurements of serum and urine creatinine and $24 \mathrm{~h}$ proteinuria, according to a protocol previously described [16]. None of the patient had decreased creatinine clearance (range $88-194 \mathrm{ml} / \mathrm{min} / 1.73 \mathrm{~m}^{2}$ ). Serum creatinine ranged from 0.035 to $0.11 \mathrm{mmol} / \mathrm{l}$. Thirty-one percent of the patients had mild proteinuria (between 150 and $262 \mathrm{mg} / 24 \mathrm{~h}$ ). Two patients had, when poorly controlled, proteinuria of 510 and $580 \mathrm{mg} / 24 \mathrm{~h}$ respectively. The rest of the patients had proteinuria below $150 \mathrm{mg} / 24 \mathrm{~h}$.

\section{Normal Controls}

Thirty-six normal young volunteers, (19 males and 17 females) were studied. The mean age of the male population was $14 \pm 0.9$ years (SEM) (range 9-23 years). The age of the female group ranged from 6 to 22 years with a mean of $15 \pm 1$ years. Seventyone percent was post-menarchial. The mean weight of the normal volunteers was within $10 \%$ of ideal body weight. They were recruited, in the majority, from the population of middle and high schools, in Charleston and they were included in the study only if they had no history of drug intake, intercurrent or chronic disease and no family history of diabetes or coronary heart disease. Sixteen percent of the males and $35 \%$ of the females were black, the rest were Caucasoid.

Informed consent was obtained from all patients and normal subjects over 18 years of age. Parental informed consent was obtained for minors.

\section{Analytical Methods}

Blood samples were collected in EDTA $(1 \mathrm{mg} / \mathrm{ml}$ of blood), after an overnight fast and refrigerated $\left(4{ }^{\circ} \mathrm{C}\right)$ immediately. The separation of lipoproteins was performed by sequential ultracentrifugation [17] on a preparative ultracentrifuge (Beckman L5-50) using a fixed-angle rotor (type 50) with appropriate adaptors.

Plasma $(3-4 \mathrm{ml})$ was layered under a $0.188 \mathrm{~mol} / 1$ saline solution containing $1 \mathrm{mmol} / \mathrm{l}$ of EDTA $(\mathrm{d}=1.006 \mathrm{~g} / \mathrm{ml})$ and spun for $18 \mathrm{~h}$ at $40,000 \mathrm{rev} / \mathrm{min}$ at $16^{\circ} \mathrm{C}$. Very low density lipoproteins (VLDL) were sliced from the top layer. The infranatant solution was adjusted to a density of $1.063 \mathrm{~g} / \mathrm{ml}$ with $\mathrm{NaCl}$ and recentrifuged, for $22 \mathrm{~h}$ in the same condition. Low density lipoproteins (LDL) were removed from the top layer and the infranatant used for analysis of HDL. The recovery rate of cholesterol and triglycerides in lipoproteins ranged from 92 to $100 \%$.

Cholesterol and triglycerides were measured using the semiautomated method standardized by the Lipid Research Clinics Program [18]. The interassay coefficient of variation is $1.2 \%$ for cholesterol and $1.9 \%$ for triglycerides in our laboratory. Plasma glucose was assayed, within $2 \mathrm{~h}$ of the blood collection, using the glucose oxidase method as adapted for use in the Beckman glucose analyzer [19]. Urinary glucose excretion was determined by the two drop Clinitest method (copper sulphate) [20]. Haemaglobin $A_{1 c}\left(H_{b} A_{1 c}\right)$ was separated by isoelectric focussing of erythrocyte haemolysates on a polyacrylamide slab gel over a $\mathrm{pH}$ gradient of 6-8 using the method of Spicer et al. [21] with slight modifications. The relative concentration of $\mathrm{HbA}_{1 \mathrm{c}}$ was expressed as a percentage of the total haemoglobin. Control levels were determined in 99 normal young adults. The range (mean $\pm 2 \mathrm{SD}$ ) of normal $\mathrm{HbA}_{1 \mathrm{c}}$ levels was from 4.0 to $6.7 \%$. The interassay coefficient of variation of the method is $11 \%$.

\section{Data Analysis}

The male and female diabetic groups were subdivided into three subgroups: "good", fair and poor, according to the degree of control of their diabetes. Patients were considered as being in "good" control when their urinary glucose excretion was less than $5 \%$ of total dietary available glucose and the $\mathrm{HbA}_{1 \mathrm{c}}$ was below $10 \%$. Fair control was defined by $\mathrm{HbA}_{1 \mathrm{c}}$ levels between 10 and $13 \%$ and urinary glucose excretion between 5 and $10 \%$ of total available dietary glucose. Patients were considered in poor control when the excretion of urinary glucose exceeded $10 \%$ of total available dietary glucose and $\mathrm{HbA}_{1 \mathrm{c}}$ exceeded $13 \%$. Dietary available glucose was calculated using Woodyatt's formula [22]. Urinary glucose excretion was assayed daily by a semiquantitative method as described in Methods. At least four urine collections (before breakfast, before lunch or after school, before dinner and before bed-time) were recorded daily by the patient or parents. Once a week and on the day preceding the clinic visit a $24 \mathrm{~h}$ urine was collected and assayed similarly. The patients were classified in the subgroups of poor, "good" and fair control by assessing the records of the 2-3 weeks preceding the clinic visit. Blood for lipid and lipoprotein analysis as well as $\mathrm{HbA}_{1 \mathrm{c}}$ was obtained at the clinic visit. In $19 \%$ of the observations ( $9 \%$ of the patients) $\mathrm{HbA}_{1 \mathrm{c}}$ was 
Table 1. Fasting plasma lipid, lipoprotein and glucose levels in normal and diabetic subjects

\begin{tabular}{|c|c|c|c|c|c|}
\hline & \multirow[b]{2}{*}{ Normal control } & \multicolumn{4}{|l|}{ Diabetics } \\
\hline & & "Good" control" & Fair control $^{\mathrm{a}}$ & Poor control ${ }^{\mathrm{a}}$ & $\mathrm{p}^{\mathrm{b}}$ \\
\hline Males & subjects & & & & \\
\hline No. subjects & 19 & 28 & 18 & 24 & \\
\hline Total cholesterol (mmol/l) & $\begin{array}{c}4.16 \pm 0.75 \\
(2.64-5.84)\end{array}$ & $\begin{array}{c}4.40 \pm 0.83 \\
(3.23-5.87)\end{array}$ & $\begin{array}{c}4.63 \pm 1.06 \\
(3.13-6.96)\end{array}$ & $\begin{array}{c}5.22 \pm 1.32 \\
(3.34-7.50)\end{array}$ & $<0.01$ \\
\hline LDL-cholesterol (mmol/1) & $\begin{array}{c}2.30 \pm 0.57 \\
(1.47-3.34)\end{array}$ & $\begin{array}{c}2.38 \pm 0.67 \\
(1.22-3.96)\end{array}$ & $\begin{array}{c}2.82 \pm 1.01 \\
(1.40-5.28)\end{array}$ & $\begin{array}{c}3.34 \pm 0.93 \\
(1.40-5.17)\end{array}$ & $<0.001$ \\
\hline VLDL-cholesterol (mmol/1) & $\begin{array}{c}0.52 \pm 0.26 \\
(0.18-0.93)\end{array}$ & $\begin{array}{c}0.57 \pm 0.31 \\
(0.16-1.40)\end{array}$ & $\begin{array}{c}0.57 \pm 0.23 \\
(0.21-1.01)\end{array}$ & $\begin{array}{c}0.98 \pm 0.65 \\
(0.21-3.17)\end{array}$ & $<0.002$ \\
\hline HDL-cholesterol (mmol/l) & $\begin{array}{c}1.37 \pm 0.31 \\
(1.01-2.28)\end{array}$ & $\begin{array}{c}1.47 \pm 0.23 \\
(1.01-1.84)\end{array}$ & $\begin{array}{c}1.29 \pm 0.23 \\
(0.93-1.76)\end{array}$ & $\begin{array}{c}0.96 \pm 0.28 \\
(0.57-1.86)\end{array}$ & $<0.0001$ \\
\hline Triglycerides (mmol/l) & $\begin{array}{c}0.95 \pm 0.36 \\
(0.15 \pm 1.69)\end{array}$ & $\begin{array}{c}0.88 \pm 0.45 \\
(0.32-2.60)\end{array}$ & $\begin{array}{c}1.16 \pm 0.56 \\
(0.56-2.37)\end{array}$ & $\begin{array}{c}1.82 \pm 0.88 \\
(0.90-4.69)\end{array}$ & $<0.0001$ \\
\hline VLDL-triglycerides ( $\mathrm{mmol} / \mathrm{l})$ & $\begin{array}{c}0.58 \pm 0.37 \\
(0.11-1.34)\end{array}$ & $\begin{array}{c}0.55 \pm 0.45 \\
(0.18-2.19)\end{array}$ & $\begin{array}{c}0.81 \pm 0.53 \\
(0.24-1.76)\end{array}$ & $\begin{array}{c}1.30 \pm 0.85 \\
(0.37-4.07)\end{array}$ & $<0.001$ \\
\hline Glucose $(\mathrm{mmol} / \mathrm{l})$ & $\begin{array}{c}4.44 \pm 0.50 \\
(3.44-5.11)\end{array}$ & $\begin{array}{c}4.61 \pm 2.78 \\
(2.22-10.71)\end{array}$ & $\begin{array}{c}9.05 \pm 4.94 \\
(2.50-19.87)\end{array}$ & $\begin{array}{l}15.99 \pm 5.66 \\
(2.66-25.64)\end{array}$ & $<0.0001$ \\
\hline \multicolumn{6}{|l|}{ Females } \\
\hline No. subjects & 17 & 20 & 20 & 18 & \\
\hline Total cholesterol $(\mathrm{mmol} / \mathrm{l})$ & $\begin{array}{c}4.14 \pm 0.85 \\
(2.87-5.82)\end{array}$ & $\begin{array}{c}4.47 \pm 0.65 \\
(3.28-5.28)\end{array}$ & $\begin{array}{c}4.73 \pm 1.06 \\
(3.39-6.91)\end{array}$ & $\begin{array}{c}6.49 \pm 2.17 \\
(4.27-13.66)\end{array}$ & $<0.0002$ \\
\hline LDL-cholesterol (mmol/l) & $\begin{array}{c}2.48 \pm 0.65 \\
(1.78-3.59)\end{array}$ & $\begin{array}{c}2.64 \pm 0.52 \\
(1.86-3.39)\end{array}$ & $\begin{array}{c}3.03 \pm 0.96 \\
(1.50-4.89)\end{array}$ & $\begin{array}{c}3.96 \pm 1.03 \\
(2.41-6.05)\end{array}$ & $<0.001$ \\
\hline VLDL-cholesterol $(\mathrm{mmol} / 1)$ & $\begin{array}{c}0.39 \pm 0.31 \\
(0.13-0.91)\end{array}$ & $\begin{array}{c}0.52 \pm 0.23 \\
(0.16-0.89)\end{array}$ & $\begin{array}{c}0.54 \pm 0.36 \\
(0.13-1.73)\end{array}$ & $\begin{array}{c}1.45 \pm 1.37 \\
(0.34-6.54)\end{array}$ & $<0.0001$ \\
\hline HDL-cholesterol (mmol/l) & $\begin{array}{c}1.32 \pm 0.28 \\
(1.01-1.97)\end{array}$ & $\begin{array}{c}1.34 \pm 0.18 \\
(1.01-1.68)\end{array}$ & $\begin{array}{c}1.24 \pm 0.26 \\
(0.85-1.94)\end{array}$ & $\begin{array}{c}1.06 \pm 0.31 \\
(0.65-1.94)\end{array}$ & $<0.001$ \\
\hline Triglycerides (mmol/1) & $\begin{array}{c}0.98 \pm 0.26 \\
(0.62-1.6)\end{array}$ & $\begin{array}{c}0.98 \pm 0.54 \\
(0.44-1.94)\end{array}$ & $\begin{array}{c}1.20 \pm 0.68 \\
(0.50-2.99)\end{array}$ & $\begin{array}{l}2.8 \pm 2.8 \\
(0.62-12.65)\end{array}$ & $<0.005$ \\
\hline VLDL-triglycerides $(\mathrm{mmol} / \mathrm{l})$ & $\begin{array}{c}0.59 \pm 0.26 \\
(0.20-1.25)\end{array}$ & $\begin{array}{c}0.69 \pm 0.54 \\
(0.17-2.26)\end{array}$ & $\begin{array}{c}0.79 \pm 0.56 \\
(0.18-2.26)\end{array}$ & $\begin{array}{l}2.15 \pm 2.5 \\
(0.32-11.11)\end{array}$ & $<0.01$ \\
\hline Glucose $(\mathrm{mmol} / \mathrm{l})$ & $\begin{array}{c}4.38 \pm 0.39 \\
(3.72-5.11)\end{array}$ & $\begin{array}{c}7.44 \pm 2.72 \\
(2.22-11.38)\end{array}$ & $\begin{array}{l}10.44 \pm 3.72 \\
(2.89-19.15)\end{array}$ & $\begin{array}{l}15.60 \pm 7.05 \\
(5.22-28.31)\end{array}$ & $<0.001$ \\
\hline
\end{tabular}

Results are expressed as mean $\pm \mathrm{SD}$ (range is shown in parentheses)

a Criteria for assessment of control are defined in Subjects and Methods

b Level of significance based upon Mann-Whitney $U$ Test comparing patients in poor control to patients in good control and normals

not measured and the urinary excretion of glucose was the only criterion used for classification. Only two patients showed discordance between $\mathrm{HbA}_{1 \mathrm{c}}$ and urinary glucose by these criteria and they were excluded from the study. Some patients were studied more than once in the same degree of control and their lipid and lipoprotein levels were averaged. Fourteen males and eight females were studied on different occasions in different degrees of control and they were included as an independent observation in each patient subgroup. The maximum number of patients who were included in any two of these subgroups was six for males and three for females.

There were no differences in the mean age of the three subgroups either in males or in females. The number of post-menarchial females was similar in all female subgroups (70,67 and $65 \%$ respectively in the groups in fair, poor and "good" control).
The percentage of blacks was similar in all subgroups in males; 21,23 and $25 \%$ in poor, fair and "good" control respectively. In females there was a greater proportion of blacks in the poorly controlled group; 72,40 and $45 \%$ in the groups with poor, fair and "good" control.

An analysis of variance was performed comparing the several subgroups of patients and the normal controls for each lipid and lipoprotein. Age, race and pubertal status were introduced as independent variables. Thus, the effects of age, race and pubertal status of the subjects were eliminated in the final comparison between the groups. Each sex was analyzed separately. Non-parametric analysis using Mann-Whitney $U$ test was also used to compare differences in means between groups. Spearman rank correlations were performed between all the variables studied. 


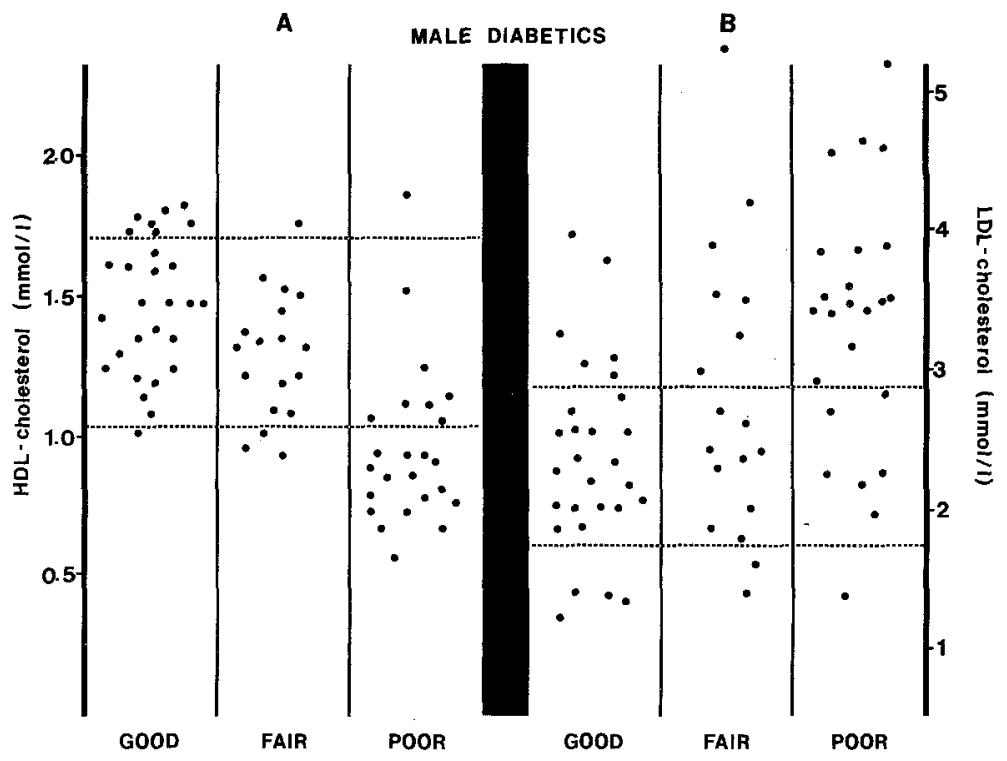

A

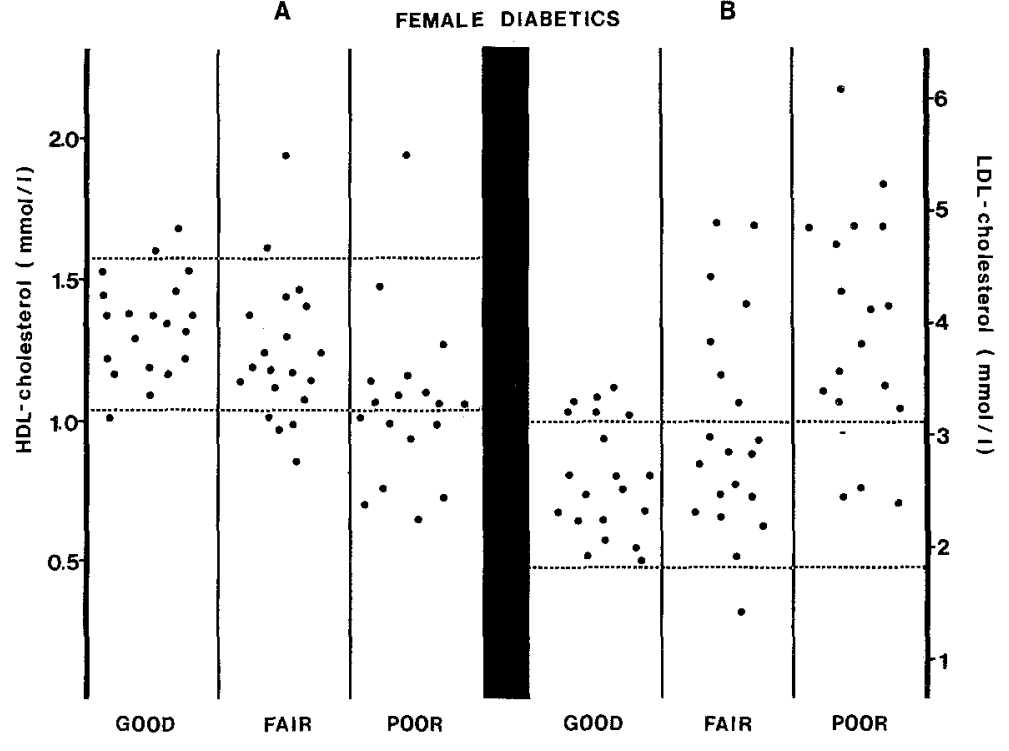

Fig. 1. HDL (A) and LDL (B) cholesterol levels in male diabetic patients in good, fair and poor control. The broken lines represent the mean \pm 1 SD. Ninety-five percent of the normal control subjects had HDL cholesterol levels within this range (only one subject had a higher level). Eighty-nine percent had LDL cholesterol levels within the above range (one subject had a higher level and another had a lower level)

\section{Results}

Table 1 summarizes the laboratory studies in the male and female populations. Poorly controlled diabetic patients of both sexes had significantly increased levels of total, LDL and VLDL cholesterol as well as triglycerides and VLDL triglycerides when compared with diabetic patients in "good" control and normals. On the other hand the levels of HDL cholesterol were significantly decreased. Patients in fair control, in both sexes, showed significant changes only in the plasma glucose levels when compared with normal subjects. Figures 1 and 2 show the levels of HDL and LDL cholesterol in the different subgroups of male and female patients. There is slight overlap in HDL cholesterol levels between the groups in poor and good control in both sexes, the overlap being more marked in females than in males. In contrast a smaller overlap of the LDL cholesterol levels between groups in good and poor control was observed in females.

The correlations between all of the variables studied were analyzed using the Spearman rank correlation test (Table 2). All the lipid and lipoprotein 
Table 2. Correlation coefficients ${ }^{\mathrm{a}}$ between lipids, lipoproteins, glucose and haemoglobin $\mathrm{A}_{1 \mathrm{c}}$ in diabetic patients

\begin{tabular}{|c|c|c|c|c|c|c|c|}
\hline & $\begin{array}{l}\text { Total } \\
\text { cholesterol }\end{array}$ & $\begin{array}{l}\text { LDL } \\
\text { cholesterol }\end{array}$ & $\begin{array}{l}\text { HDL } \\
\text { cholesterol }\end{array}$ & $\begin{array}{l}\text { VLDL } \\
\text { cholesterol }\end{array}$ & Triglycerides & $\begin{array}{l}\text { VLDL } \\
\text { triglycerides }\end{array}$ & Glucose \\
\hline \multicolumn{8}{|l|}{ Males $^{b}$} \\
\hline LDL-cholesterol & 0.80 & & & & & & \\
\hline HDL-cholesterol & -0.18 & -0.22 & & & & & \\
\hline VLDL-cholesterol & 0.50 & 0.19 & -0.44 & & & & \\
\hline Triglycerides & 0.39 & 0.31 & -0.62 & 0.53 & & & \\
\hline VLDL-triglycerides & 0.35 & 0.24 & -0.61 & 0.59 & 0.95 & & \\
\hline Glucose & 0.18 & 0.22 & -0.40 & 0.21 & 0.28 & 0.23 & \\
\hline Haemoglobin $A_{1 c}$ & 0.38 & 0.35 & -0.63 & 0.29 & 0.48 & 0.47 & 0.54 \\
\hline \multicolumn{8}{|l|}{ Females $^{\mathrm{c}}$} \\
\hline LDL-cholesterol & 0.84 & & & & & & \\
\hline HDL-cholesterol & -0.16 & -0.21 & & & & & \\
\hline VLDL-cholesterol & 0.64 & 0.31 & -0.43 & & & & \\
\hline Triglycerides & 0.33 & 0.17 & -0.58 & 0.68 & & & \\
\hline VLDL-triglycerides & 0.27 & 0.10 & -0.52 & 0.61 & 0.95 & & \\
\hline Glucose & 0.33 & 0.43 & -0.41 & 0.22 & 0.45 & 0.37 & \\
\hline Haemoglobin $\mathrm{A}_{1 \mathrm{c}}$ & 0.38 & 0.43 & -0.59 & 0.38 & 0.54 & 0.45 & 0.67 \\
\hline
\end{tabular}

a Determined by the Spearman rank correlation test

b For $\mathrm{r} \geqslant 0.246$ and $<0.320, \mathrm{p}<0.05$; for $\mathrm{r} \geqslant 0.32, \mathrm{p}<0.01$

c For $\mathrm{r} \geqslant 0.266$ and $<0.345, \mathrm{p}<0.05$; for $\mathrm{r} \geqslant 0.345, \mathrm{p}<0.01$

A

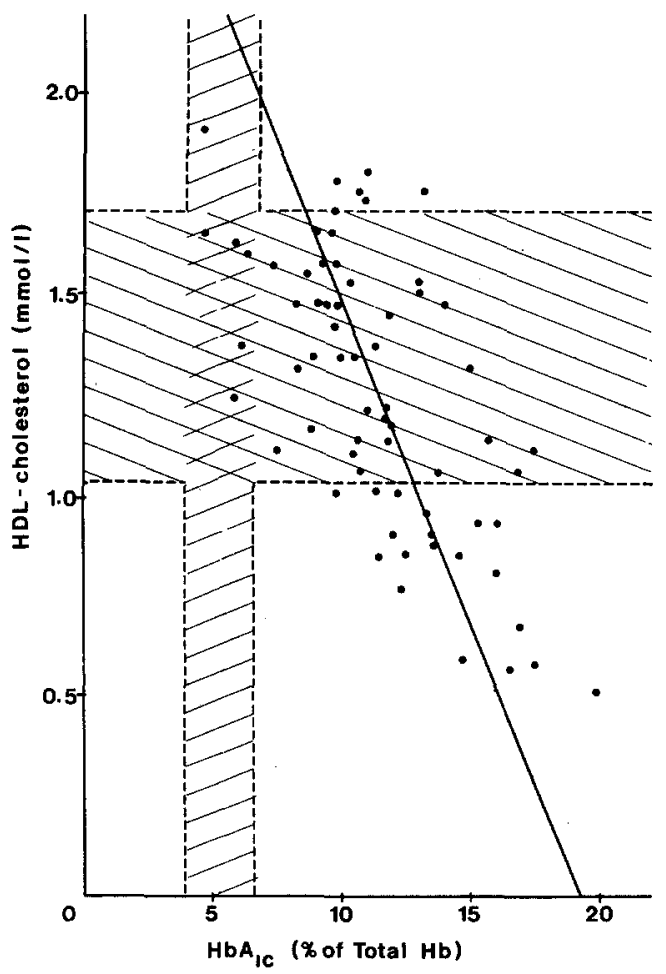

MALE DIABETICS

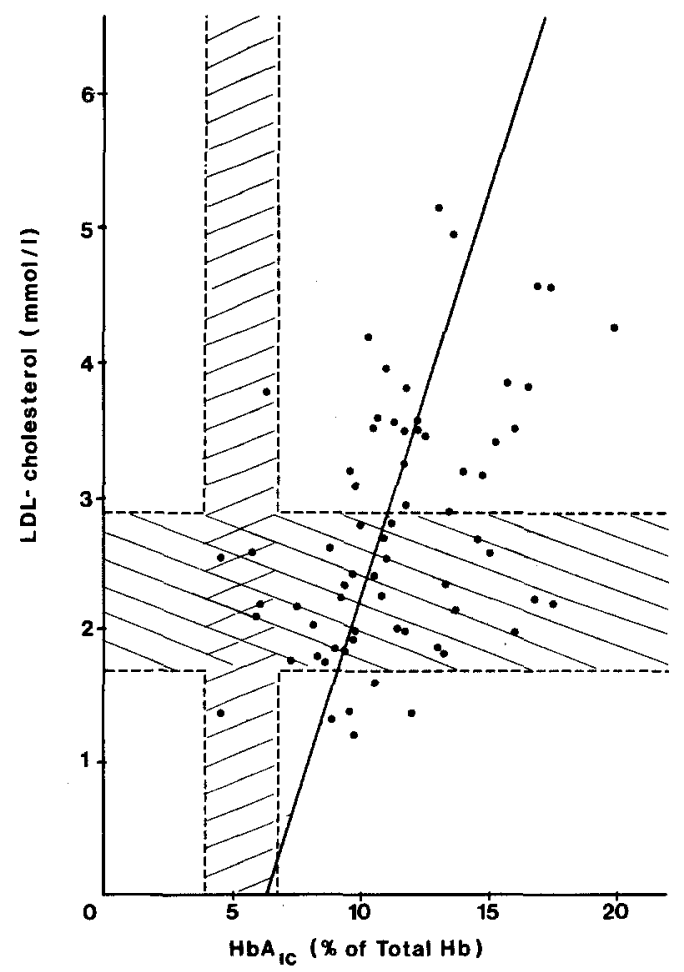

Fig. 3. Correlation coefficients between $\mathrm{HbA}_{1 \mathrm{c}}$ and $\mathrm{HDL}$ cholesterol $(\mathrm{A})(\mathrm{r}=-0.63, \mathrm{p}<0.01)$ and between $\mathrm{Hb} \mathrm{A}_{1 \mathrm{c}}$ and $\mathrm{LDL}$ cholesterol (B) $(\mathrm{r}=0.35, \mathrm{p}<0.01)$ in male diabetic patients ( 67 observations in 51 patients). The hatched zones represent for $\mathrm{Hb} \mathrm{A}_{1 \mathrm{c}}$ the mean $\pm 2 \mathrm{SD}$ of the normal levels in our laboratory; for HDL and LDL cholesterol they represent the mean $\pm 1 \mathrm{SD}$. Ninety-five percent of the normal control subjects had HDL cholesterol levels within this range (only one subject had a higher level). Eighty-nine percent had LDL cholesterol levels within the limits represented (one subject had a higher level and another had a lower level) 
A

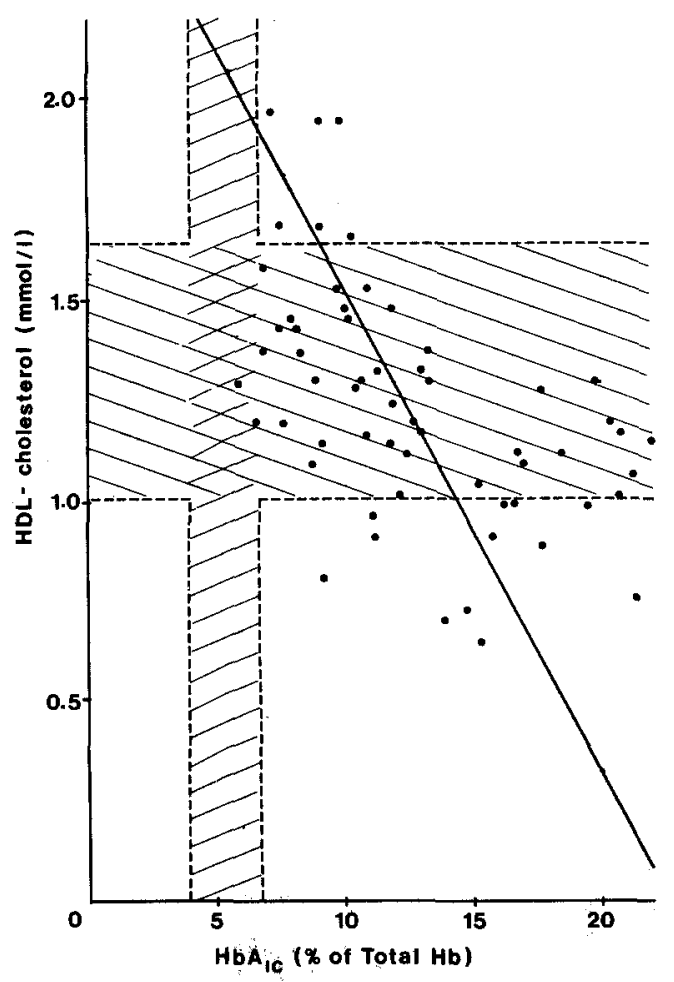

B

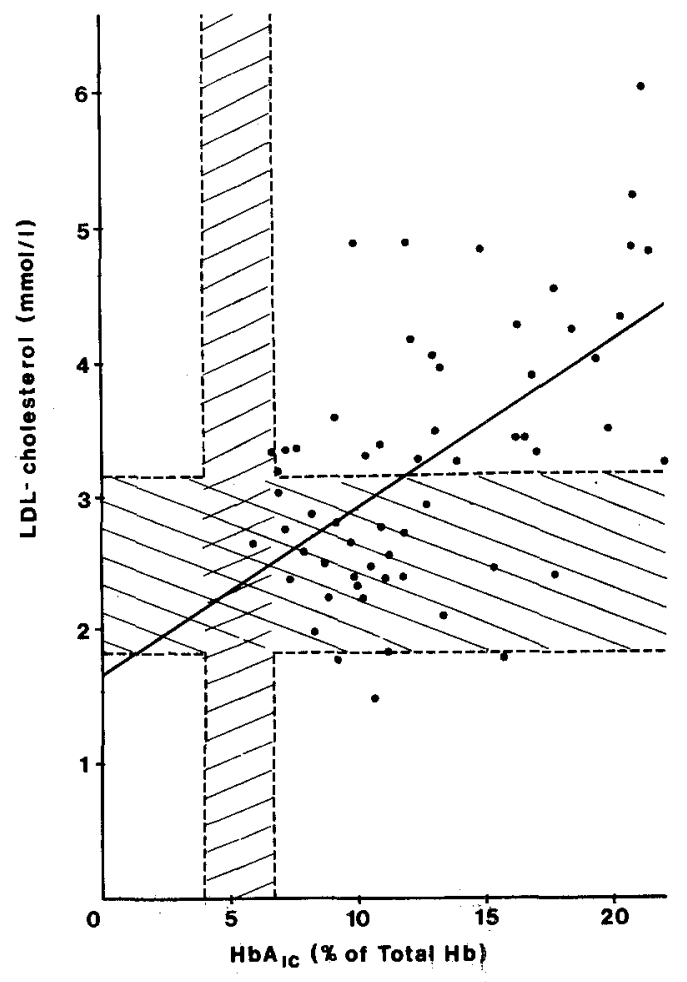

Fig. 4. Correlation coefficients between $\mathrm{HbA}_{1 \mathrm{c}}$ and $\mathrm{HDL}$ cholesterol $(\mathrm{A})(\mathrm{r}=0.59, \mathrm{p}<0.01)$ and between $\mathrm{Hb} \mathrm{A}_{1 \mathrm{c}}$ and $\mathrm{LDL}$ cholesterol (B) $(r=0.43, p<0.01)$ in female diabetic patients ( 59 observations in 45 patients). The hatched zones represent for $\mathrm{HbA}_{1 \mathrm{c}}$ the mean $\pm 2 \mathrm{SD}$ of the normal levels in our laboratory; for HDL and LDL cholesterol they represent the mean $\pm 1 \mathrm{SD}$. Ninety-five percent of the normal control group had HDL and LDL cholesterol levels within the choșen limits (one subject had higher levels)

levels were significantly correlated with $\mathrm{HbA}_{1 \mathrm{c}}$ in both sexes. In males the correlation of $\mathrm{HbA}_{1 \mathrm{c}}$ with HDL cholesterol was the strongest $(r=-0.63$, $\mathrm{p}<0.01$ ). A less strong, although significant correlation with LDL cholesterol was also found $(r=0.35$, $\mathrm{p}<0.01$ ) (Fig. 3). In Figure 4 the correlations between HDL and $\mathrm{HbA}_{1 \mathrm{c}}(\mathrm{r}=-0.59, \mathrm{p}<0.01)$ and between $\mathrm{LDL}$ and $\mathrm{HbA}_{1 \mathrm{c}}(\mathrm{r}=0.43, \mathrm{p}<0.01)$ are represented for the female group. A strong correlation $(p<0.01)$ was found between HDL and triglycerides in both sexes $(\mathrm{r}=-0.61$ for males and $\mathrm{r}=-0.58$ for females). Fasting glucose levels were significantly correlated in the male population with HDL cholesterol $(\mathrm{r}=-0.40, \mathrm{p}<0.01)$; with $\mathrm{HbA}_{1 \mathrm{c}}$ $(\mathrm{r}=0.54, \mathrm{p}<0.01)$ and with triglycerides $(\mathrm{r}=0.28$, $\mathrm{p}<0.05)$.

Plasma glucose levels were significantly correlated with $\mathrm{HbA}_{1 \mathrm{c}}(\mathrm{r}=0.67, \mathrm{p}<0.01)$, triglycerides $(\mathrm{r}=0.45, \mathrm{p}<0.01), \mathrm{LDL}(\mathrm{r}=0.43, \mathrm{p}<0.01), \mathrm{HDL}$ $(\mathrm{r}=-0.41, \mathrm{p}<0.01)$, VLDL-triglycerides $(\mathrm{r}=$ $0.37, \mathrm{p}<0.01)$ and total cholesterol $(\mathrm{r}=0.33$, $\mathrm{p}<0.05)$ in the female group.

\section{Discussion}

It is generally accepted that uncontrolled diabetes is associated with lipoprotein abnormalities but there is no agreement concerning the predominant characteristics of these abnormalities $[14,15,23-25]$. In most published reports insulin and insulin independent diabetics were not clearly distinguished when the results were analyzes and in most instances a good correlation of lipid and lipoprotein levels with the control of diabetes was lacking.

Nikkila and Hormila [14] recently studied a homogeneous group of insulin dependent, middle aged diabetics and found control-related differences in total and VLDL cholesterol in men only and in triglycerides and VLDL triglycerides in both sexes. No control-related differences were found in this group of patients for LDL or HDL cholesterol levels, in either sex. The comparison between well and poorly controlled diabetics in the above study was based on fasting blood glucose levels.

In contrast, Calvert et al. [23] found in a group of middle-aged diabetics that HDL cholesterol levels 
were decreased in patients in poor metabolic control and they significantly increased after appropriate treatment with insulin. The number of insulin treated patients in this study was however small and it is not completely clear if the patients were insulin-dependent or merely insulin-treated.

Most studies of lipids and lipoproteins in insulindependent diabetics have been performed in children and adolescents and again the abnormalities found are somewhat contradictory. Tamborlane et al. [24], in a group of non-obese ketosis-prone diabetics of both sexes (mostly adolescents) found a significant decrease of total cholesterol and triglycerides after treatment with insulin. Mann et al. [25] found similar results in children. They observed either hypertriglyceridaemia or hypercholesterolaemia or both in poorly controlled children of both sexes. Neither of the above authors measured lipoproteins. In contrast, Chase and Glasgow [15] reported in diabetic children, considered to be in good control, a significant increase of total cholesterol, triglycerides and LDL and decreased levels of HDL.

Our present study was performed in insulindependent diabetic children and young adults, and the analysis of results was based on the degree of metabolic control, as assessed, in its majority, by $24 \mathrm{~h}$ glycosuria and $\mathrm{HbA}_{1 \mathrm{c}}$ levels. The concordance of the two parameters in the population studied supports the validity of the assessment of control. While $24 \mathrm{~h}$ glycosuria is often not a valid indicator of control in adults due to the changes in renal threshold associated with diabetic nephropathy, it appears to be a reliable index in children and young adults [26] even with the semiquantitative method used, provided that multiple analyses are performed.

Our results showed that insulin-dependent diabetics in good and fair control do not differ significantly from normal volunteers. In contrast, poorly controlled diabetics of both sexes show a significant increase in all lipids and lipoproteins with the exception of HDL cholesterol which was significantly decreased.

Even after taking into consideration small differences in the composition of the groups with respect to race, age and pubertal status (female group) between the normal controls and the three subgroups of diabetics, there were very significant differences between the groups for each lipid and lipoprotein studied. Thus, we confirmed the observations reporting a decrease in total cholesterol and triglycerides with control of diabetes $[24,25]$ and expanded these observations by finding similar results for VLDLcholesterol VLDL-triglycerides and LDL cholesterol.
The most important observation however in the present study is the finding of control-related-differences in HDL cholesterol. The association in the insulin-dependent diabetics in poor metabolic control, of increased LDL cholesterol and decreased HDL cholesterol, both well known risk factors of coronary heart disease, may contribute to the greater incidence of that disease in diabetics.

The mechanisms responsible for the alteration of plasma lipoprotein levels in insulin-dependent diabetes are not entirely clear. An attractive hypothesis which may explain the HDL response is the one postulated by Tall and Small [27]. They suggested that accelerated formation of HDL takes place when increased circulating triglyceride-carrying lipoproteins are associated with normal or enhanced lipoprotein lipase activity. Since in insulin deficient diabetic patients lipoprotein lipase activity is decreased, while VLDL and chylomicrons are usually elevated, the activation of lipoprotein lipase by insulin therapy may account for the increase of HDL levels after appropriate insulin treatment.

Finally, it is noteworthy that as a group not only the diabetics in good control but also the ones in fair control presented relatively normal levels of lipids and lipoproteins. However, the strong correlation of $\mathrm{HbA}_{1 \mathrm{c}}$ with plasma lipids and lipoproteins suggest that the latter levels may represent an index of metabolic regulation in young insulin dependent diabetic patients.

Acknowledgements. We thank Dr. J. A. Colwell for his encouragement and support; Ms Gracie Farrow, Beth Malenkos and Mr. Jeff Jenkinson for excellent technical assistance and Ms Julia Brandon for secretarial help. Supported in part by Veterans Administration Research Funds and by grants from the Medical University of South Carolina Biomedical Research Appropriation, the South Carolina Chapter of the American Diabetes Association and grant AM-02001 from the National Institutes of Arthritis, Metabolism and Digestive Diseases. Dr. Lopes-Virella is the recipient of a Special Emphasis Research Career Development Award in Diabetes Mellitus/Cardiovascular (1-K01-AM00591), from the NHLBI and NIAMDD.

\section{References}

1. Root HF, Bland EF, Gordon WH (1939) Coronary atherosclerosis in diabetes mellitus. JAMA 113: 27-30

2. Bradley RF (1971) Cardiovascular disease In: Markle A, White R, Bradley RF, Krall LD (eds) Diabetes mellitus. Lea and Febiger, Philadelphia, pp 417-477

3. Garcia MJ, McNamara PM, Gordon T, Kannel WB (1974) Morbidity and mortality in diabetes in the Framingham population. Diabetes 23: 105-111

4. Albrink MJ, Lavietes PH, Mann EB (1963) Vascular disease and serum lipids in diabetes mellitus: observations of 30 years. Ann Intern Med 58: 305-323

5. Santen RJ, Willis PW, III, Fajans SS (1972) Atherosclerosis in 
diabetes mellitus. Correlations in the serum lipid levels, adiposity and serum insulin level. Arch Intern Med 130: 833-843

6. Nikkila EA (1973) Triglyceride metabolism in diabetes mellitus. Prog Biochem Pharmacol 8: 271-299

7. New MI, Roberts TN, Bierman EL (1963) The significance of blood lipid alterations in diabetes mellitus. Diabetes 12: 208-212

8. Lopes-Virella MFL, Gonzalez J, Rosebrock G, Lichtenstein L, Sagel J, Colwell JA (1977) High density lipoprotein cholesterol and apolipoprotein $A$ levels in diabetics with and without macrovascular disease. Diabetes 25: 31

9. Miller GJ, Miller Ne (1975) Plasma high-density lipoprotein concentration and development of ischaemic heart disease. Lancet I: $16-19$

10. Berg R, Borresen AL, Dahlen G (1976) Serum high-density lipoprotein and atherosclerotic heart disease. Lancet I: 499-501

11. Gordon T, Castelli WP, Hjortland MC, Kannel WS, Dawber TR (1977) High density lipoprotein as a protective factor against coronary heart disease. Am J Med 62: 707-719

12. Streja D, Steiner G, Kwiterovich PO (1978) Plasma high density lipoproteins and ischemic heart disease. Ann Intern Med 89: 871-880

13. Lopes-Virella MFL, Stone PG, Colwell JA (1977) Serum high density lipoprotein in diabetic patients. Diabetologia 13: 285-291

14. Nikkila EA, Hormila $P$ (1978) Serum lipids and lipoproteins in insulin treated diabetes. Demonstration of increased high density lipoprotein concentrations. Diabetes 27: 1078-1086

15. Chase PH, Glasgow AM (1976) Juvenile diabetes and serum lipids and lipoprotein levels. Am J Dis Child 130: 1113-1117

16. Lopes-Virella MF, Virella G, Rosebrock G, Sagel J, Gonzalez J, Colwell JA (1979) Early diagnosis of renal malfunction in diabetes. Diabetologia 16: 165-171

17. Havel RJ, Eden HA and Bragdon JH (1955) The distribution and chemical composition of ultracentrifugally separated lipoproteins in human serum. J Clin Invest 34: 1345-1353

18. Manual of Lipid Operations, Lipid Research Clinics Program
(1974) Lipid and lipoprotein analysis, Vol I. Department of Health, Education and Welfare, Publ No (NIH) 75-628

19. Kadish AH, Little RL, Sternberg JC (1968) A new and rapid method for the determination of glucose by measurement of rate of oxygen consumption. Clin Chem 14: 116-131

20. Belmonte MM, Sarkozy E, Harper ER (1967) Urine sugar determination by the two drop Clinitest method. Diabetes 16: 557-559

21. Spicer KM, Allen RC, Buse MG (1978) A simplified assay of hemoglobin $A_{1 c}$ in diabetic patients using isoelectric focusing and quantitative microdensitometry. Diabetes 27: 384-388

22. Colwell AR (1977) Diabetes mellitus in general practice. Yearbook Publishers, Chicago, P 111

23. Calvert GD, Mannik T, Graham JJ, Wise PH, Yates RA (1978) Effects of therapy on plasma-high-density-lipoproteincholesterol concentration in diabetes mellitus. Lancet II: 66-68

24. Tamborlane WV, Sherwin RS, Genel M, Felig P (1979) Restoration of normal lipid and amino acid metabolism in diabetic patients treated with a portable insulin-infusion pump. Lancet I: $1258-1261$

25. Mann JI, Hughson WG, Holman RR, Honour AJ, Thorogood M, Smith A, Baum JD (1978) Serum lipids in treated diabetic children and their families. Clin Endocrinol (Oxf) 8: 27-33

26. Lanoe R, Soira J, Thibult N, Soria C, Eschwege E, Tchobroutsky $G$ (1977) Glycosylated haemoglobin concentrations and clinitest results in insulin dependent diabetes. Lancet II: 1156-1157

27. Tall AR, Small DM (1978) Plasma high density lipoproteins. N Engl J Med 299: 1232-1236

Received: 15 October 1980

and in revised form: 23 March 1981

Maria F. Lopes-Virella, M. D.

Department of Medicine

Medical University of South Carolina

171 Ashley Avenue

Charleston, SC 29403, USA 